\title{
Reframing Writing Instruction in Physical Learning Environments: Making Connections Between Digital and Nondigital Technologies
}

\author{
André C. Buchenot \\ IUPUI \\ buchenot@iupui.edu \\ Tiffany A. Roman \\ Kennesaw State University \\ troman5@,kennesaw.edu
}

\begin{abstract}
Physical learning environments offer many affordances that one can choose from when designing instruction. For courses where student writing is central to course learning outcomes, a challenge exists in that innovative digital technologies may take precedence over nondigital tools, such as paper-based student writing. We argue that treating student writing as a technology can increase opportunities for active learning within physical learning environments. In this article, we describe an approach to writing instruction that builds intentional connections between paper-based texts and digital technologies to increase opportunities for active learning. We explain the rationale for the design decisions in an introductory composition course taught in a technology-enhanced, Active Learning Classroom through a design case model. Classroom applications relevant to any course in which student writing is a central learning activity are discussed.
\end{abstract}

Keywords: learning environments, active learning, student writing, course design, design case, pedagogy.

In this article, we describe an approach to writing instruction that builds intentional connections between digital technologies and nondigital technologies with a focus on the physical learning environment in which the instruction takes place. The technologies discussed include not only innovative digital tools but also familiar resources whose technological character might be obscured by routinized use. In particular, we are interested in paper-based student writing. We argue that treating paper-based student writing and other documents as technologies draws attention to their material affordances and links them with more visible, digital technologies. Further we argue that attending to these affordances and making connections with digital technologies creates opportunities for active learning across physical learning environments. In the first-year composition course examined, this approach was marshaled to help students engage in and learn about the labor of reading and writingthe physical and mental effort of understanding and composing texts - in a sustained, reflective way. In other disciplines, this approach might be adapted to serve a range of learning outcomes, including deepening content knowledge and focusing in-class discussion.

Our analysis of the design choices animating this approach to treating paper documents as a technology supports the widely documented promise of Active Learning Classrooms (ALCs; Baepler, Walker, Brooks, Saichaie, \& Petersen, 2016) while also suggesting that a more intentional application of technology might lead to better instructional outcomes in more conventional physical learning environments as well. Although digital writing activities may be more commonly discussed in instructional technology literature, we want to shift the discourse to the intentionality of using paperbased documents_-particularly student writing — in physical learning environments.

In what follows, we present a definition of technology that promotes connections among digital and nondigital technologies, including paper-based student writing. A clear picture of the 
instructional setting is established before we present a rich description of a design case (Boling, 2010; Howard, Boling, Rowland, \& Smith, 2012) that illustrates the potentials of this approach for writing instruction. To provide a rich description of the design case (see Smith, 2010), we articulate the key decisions made, the rationale behind these decisions, how design decisions were judged to be useful or not given the affordances of the learning space, and why the proposed technology of paper-based student writing was believed to be the best practice in this particular learning environment and instructional context.

\section{Defining Technology}

We define technology as any socially situated, material object that mediates human activity (Dryer, 2016; Russell, 1997). This definition places both novel, digital devices such as touch-sensitive displays and data projectors in the same conceptual category as familiar, nondigital tools such as moveable furniture and whiteboards (Koehler \& Mishra, 2009). Juxtaposing the novel and the mundane in this way highlights the tendency of a technology to become invisible as its use is embedded into everyday life, a process that Bruce and Hogan (1998) call the "disappearance of technology" (p. 270). They pointed to the landline telephone as an instructive example of this phenomenon, arguing that while it was initially an intrusion into American life, the telephone has become so routine that an individual might describe "talking" with a friend "without feeling the need to mention that the telephone was a necessary tool for that conversation to occur" (p. 270). In this example, the complex technology of the landline telephone has become so embedded in the user's life that it is subsumed into a basic human function; in effect, this technology disappears. Newer technologies such as smartphones, in contrast, have not been integrated into everyday life to the extent that they have disappeared; that is, this technology still feels like an intrusion. In fact, smartphones remain novel enough that employing them in an ALC is widely presented as an innovative design choice (e.g., Coca \& Sliško, 2017; Yip, Wong, Yick, Chan, \& Wong, 2019).

When a technology disappears, users tend to naturalize its operation, following the implicit program of its design without much reflection. Most Americans over 30, for example, are still able to answer a call on a landline telephone without giving much thought to how to hold a receiver or how loudly to speak. Such familiarity benefits a user by creating more fluid operation and, arguably, more efficient operation of technology. That same familiarity might discourage critical attention to the possibilities and limitations of a tool. Put plainly, once a technology has disappeared, it becomes easier to use but harder to consider in a critical way. One often overlooked technology is writing, which for the purposes of this article we define as a shared, linguistic symbol system (e.g., an alphabet) used to translate thought into a physical form (e.g., pixels on a screen) that can mediate human activity (e.g., reading written instructions for an assignment). Although it takes years of use, the technological character of writing disappears for most writers and simply becomes a way of being in the world (see Ong, 1982/2002, for more on the internalization of the technology of writing).

Writing's status as a technology is complicated by the fact that it depends on other technologies to come into being. Technologies for writing such as styli, touchscreens, and dry erase markers are used to bring writing into a physical space, a process Haas (1996) called writing being "made material through the use of technologies" (p. 3). These technologies for writing have physical

${ }^{1}$ It is important to note that individual users experience technology differently; there is no universal technological experience. To extend Bruce and Hogan's example, factors such as hearing impairment, poor or absent infrastructure, or a lack of financial resources might impede or prevent the disappearance of the telephone. Regardless of how embedded it becomes into everyday life, many users will continue to "see" a technology long after it has disappeared for others. See Star (1990) for more on the limits of technical networks. 
forms that mediate an individual's ability to make marks on a surface that correspond to a symbol system (i.e., to write). Using a pen and a pad of notebook paper to compose an essay, for instance, is a materially different experience from composing the same text with a virtual keyboard on a smartphone. However implicitly, writers attend to both writing as technology and technologies for writing to exploit their affordances.

The complex relationship of writing and technology is relevant for instructors because it represents opportunities to promote active learning. Attending to writing as a technology means attending to its capacity to mediate activity, a process similar to what instructors do when designing lessons with classroom technologies. We argue that making purposeful connections among technologies - digital and nondigital, visible and invisible - might lead to more intentional instruction that might be marshaled to support active learning.

\section{Methods}

\section{Participants}

The participants in this study consisted of 20 undergraduate students enrolled in a first-year writing course at an urban, midwestern university. Nineteen of the students had freshmen or sophomore standing. Students came from five different schools on campus; none were seeking degrees in English or any other major in the School of Liberal Arts. To protect students' privacy, data on age, gender identity, race, and ethnicity were not collected. The instructor was an assistant professor of English with a specialization in writing studies and a research interest in digital literacies.

\section{Procedure}

Capturing teaching and learning activities in a physical learning space requires intentional data collection activities, as one needs to examine the physical classroom features while focusing on the interactions of the instructor and the students. Small classrooms, which serve at most 24 students, are particularly suited to video platform data collection (Roman \& Uttamchandani, 2018). Video platform data involves recording classroom interactions by coupling a fixed-position camera (e.g., wall-mounted camera, external webcam) with lecture-capture software (e.g., Kaltura, Echo360) and audio recording capabilities. In this study, a high-fidelity wall-mounted camera was used in conjunction with Kaltura lecture-capture software. Such software enables an instructor to automate classroom recordings; recordings can be scheduled, started, ended, and stored on a university server automatically, streamlining the data collection and repository process. Wall-mounted cameras allow for data collection to occur without the imposition of a camera operator within classroom space (see Derry et al., 2010) or tripods positioned within the room, which is critical as the classroom in question was designed to be reconfigured. Video recordings produce data that are rich in detail and reliable. This data can be revisited and reanalyzed by multiple researchers (Derry et al., 2010; Pea, 2006).

The data collected within this study consisted of six full class session recordings that transpired between March and April 2017. In addition to video recordings, detailed analytic memos (Saldaña, 2015) were composed by the faculty member who taught the course. Additionally, 11 writing assignments (three first drafts, four revisions, two reflective pieces, and two student-assembled portfolios) were collected electronically at data collection points throughout the semester. 


\section{Analysis}

Using the video, analytic memos, and writing samples, we analyzed the findings from the study as a design case (see Boling, 2010), or a rich description of a "real artifact or experience that has been intentionally designed" (Boling, 2010, p. 1). The intent of a design case is to provide precedent for other individuals who can learn from the lessons of the case to make similar or divergent instructional decisions (Howard et al., 2012). In the sections below, we present the design judgments of the instructor through a rich description of the instructional context and argue for making purposeful connections across digital and nondigital technologies to support active learning. We are interested in how student writing in a tangible, paper-bound form might be entered into the inventory of technological options presented in a classroom-particularly in a classroom featuring prominent digital technologies as described below.

Writing Instruction and Programmatic Goals

The course described in this article was part of a first-year writing program with a shared set of curricular standards. The standards explain that the course teaches students "skills of critical reading, thinking, and writing" by asking them "to read...to analyze... and to write about" a variety of "written and cultural texts" (W131, 2018). Notably, written work from students in the class (e.g., drafts of essays, reading notes) are included in the category of "written and cultural text" described in the standards, along with scholarly articles, textbooks, and other class materials. The institutional documents continue to explain that these texts might be used to help students "develop strategies" for "reading rhetorically," "writing rhetorically," and "engag[ing] in inquiry" (W131, 2018). Rather than treating these texts simply as a static body of content to master, the course asks students to focus on how they are able to use them. This approach focuses students' and instructors' attention on the labor of reading and writing in an effort to promote abilities that might "transfer" from the first-year classroom to other writing situations (see Wardle, 2007).

\section{Physical Classroom Description}

A second context shaping design choices of the instructor was the physical learning space itself.

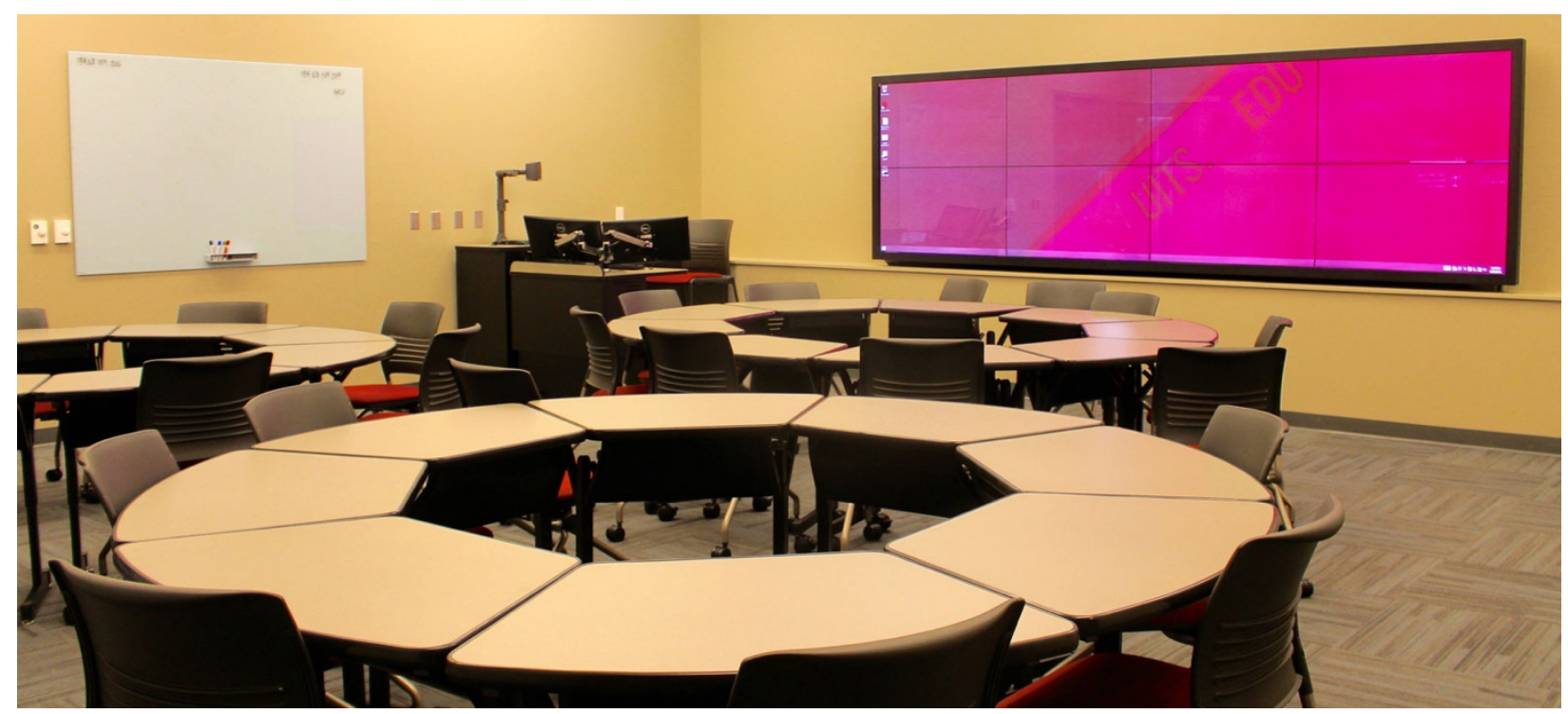

Figure 1. The Active Learning Classroom. 
The course was taught in an ALC (see Figure 1) designed to "[encourage] students to use mobile devices in conjunction with team-based learning activities to solve challenging problems and engage in hands-on collaboration" (University Information Technology Services, 2019). To that end, the room featured a wireless content-sharing system that allowed students to project information from their personal devices onto a large "interactive touch video wall" for group discussion (University Information Technology Services, 2019). Complementing these digital classroom technologies were nondigital technologies including whiteboards and moveable furniture. In describing the physical context of this ALC, we seek to highlight the specific technologies integrated into this particular space and to suggest that this integration shaped instruction. Technology-enhanced learning environments can provide a positive and significant impact on student learning when all mediating factors are held constant (Brooks, 2011). Such impacts occur in all classrooms, whether they are richly appointed or modestly provisioned. The approach to writing instruction described in this article owes something to the affordances of the classroom technologies listed above, but it could be adapted to a variety of physical learning spaces.

\section{Why Paper?}

Examining student writing during class is a familiar move in composition pedagogy. While the reasons for examining students' writing vary, the writing itself often takes a familiar form: word-processed text printed onto sheets of white paper, $8.5 \mathrm{in}$. wide and 11 in. tall. Exceptions exist-particularly in courses focused on multimodal production (see Shipka, 2011) and in situations where material conditions restrict the availability of paper (see Prendergast \& Ličko, 2009)-but computer-composed text printed or photocopied onto U.S. letter-sized paper has a long history in composition classrooms. Building on this tradition, the instructor of the course described here set course policies and designed learning activities that required students to submit their written work electronically via a learning management system no fewer than 5 hours before the scheduled class meeting time-a practice that afforded the instructor time to review submissions, select useful examples, and print paper copies to review in class. This practice enabled the regular, sustained use of paper documents. The choice to put paper at the center of a class that met in a digitally enhanced ALC might be seen as anachronistic. Why should students and instructors review paper documents in a learning space where screens are readily available? The answer, we argue, is in the intentionality of the instructional design judgment made within this particular learning context.

The affordances of paper documents can be marshaled to mediate learning in ways that are difficult and/or cost- prohibitive to replicate with digital technology. On a student draft printed on paper, for example, a student can circle a problematic phrase, draw an arrow to the margin, or jot down a response more efficiently and effectively than with most digital technologies. Similar functions are available on tablet computers but require institutions and/or students to make financial investments that far exceed the cost of photocopies and ballpoint pens. As with any technology, instructors must weigh the efficiency, access, cost, and effectiveness of the tools to be integrated. Ultimately, the instructor's decision to embrace paper was not a rejection of the digital but an attempt to put it into dialogue with a nondigital technology.

\section{Classroom Applications}

In the following sections, we describe three activities that were developed using the approach described in this article. For each activity, we discuss pedagogical goals and classroom applications. 


\section{Anonymized Student Writing}

Overview and Goal. This first application, anonymized student writing, is a process of using deidentified paper copies of student-composed drafts to facilitate writing seminars. Harris (2010) defined a writing seminar as a teacher-led "conversation about a text written by one of the students in the room," the purpose of which is to "frame a lesson on writing for everyone in the class" (p. 147). Rather than suggesting revisions for the author, class participants discuss ideas and issues they see represented in the writing in an effort to answer the question "What can we learn as writers from this text?"' (p. 147). The goal of using anonymized student writing is to allow student interest-expressed in the text under review and in the responses to it-to guide a discussion of course concepts. In firstyear composition, course concepts might include ethically representing the ideas of others through quotation and paraphrase; making and supporting claims; and topics from scholarship in the field of writing studies. In other disciplines, course concepts might include field-specific research or disciplinary writing conventions. Regardless of their content area, we argue, instructors may wish to consider using anonymized student writing in physical learning environments to encourage studentled discussion of texts, as it relates to the specific course concept identified.

Using photocopies of drafts to discuss writing is not a radical idea in writing instruction; however, thinking about student-written paper documents as technologies-as objects that mediate activity - can build on conventional uses of student writing by fostering approaches to teaching that better exploit the affordances of this and other technologies.

Connecting digital and nondigital technology. Using anonymized student writing requires an instructor to review electronically submitted student-composed texts before class to identify texts that might support a writing seminar. Using a word processor, the instructor replaces names with pseudonyms (e.g., "Student 1") and adjusts spacing and margins to allow for handwritten comments. No "corrections" are made to grammar, spelling, or style. While this work happens outside of the physical learning space, we discuss it here because (a) it shapes in-class activity and (b) it highlights the relationship between nondigital and digital iterations of student writing. The key affordance of the digital technology used in this phase (i.e., word processing software and files) is "computability," or the capacity for software to modify writing as digital data (Dush, 2015, p. 176; see also Manovich, 2001). This affordance makes it possible to more easily format documents in ways that encourage student-led discussion of texts.

After being formatted and reproduced, the anonymized student writing is distributed during class. Volunteers read each section aloud while their colleagues follow along and take notes in the margins. In the ensuing discussion, students are asked to reference the anonymized document and their notes. The key affordance of the nondigital technology used in this phase is fixity. Students can handwrite on the surface of their paper, and are encouraged to do so, but they cannot delete or rewrite the text as they could with a digital text. This affordance reinforces the writing seminar's goal: to discuss the ideas represented in the text rather than to revise the way the text is written.

The use of anonymized student writing was augmented by the moveable small tables and chairs, both on casters, in the classroom. In one representative class meeting, students began in rows turned toward the "front" of the room (see Figure 2). Then, they arranged their tables and chairs into a circle for a full-group, seminar-style discussion (see Figure 3). At the end of the large group discussion, students reflected on the seminar in pairs by turning in their seats (see Figure 4). 


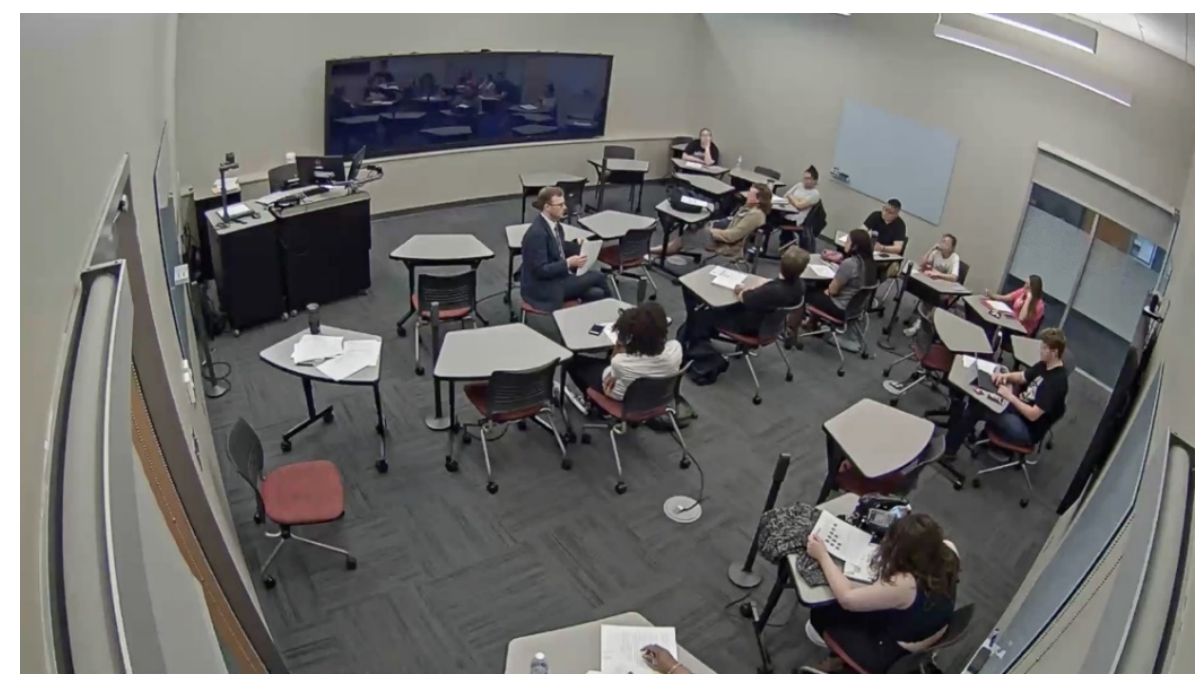

Figure 2. Students face the instructor and interactive video wall at the start of class.

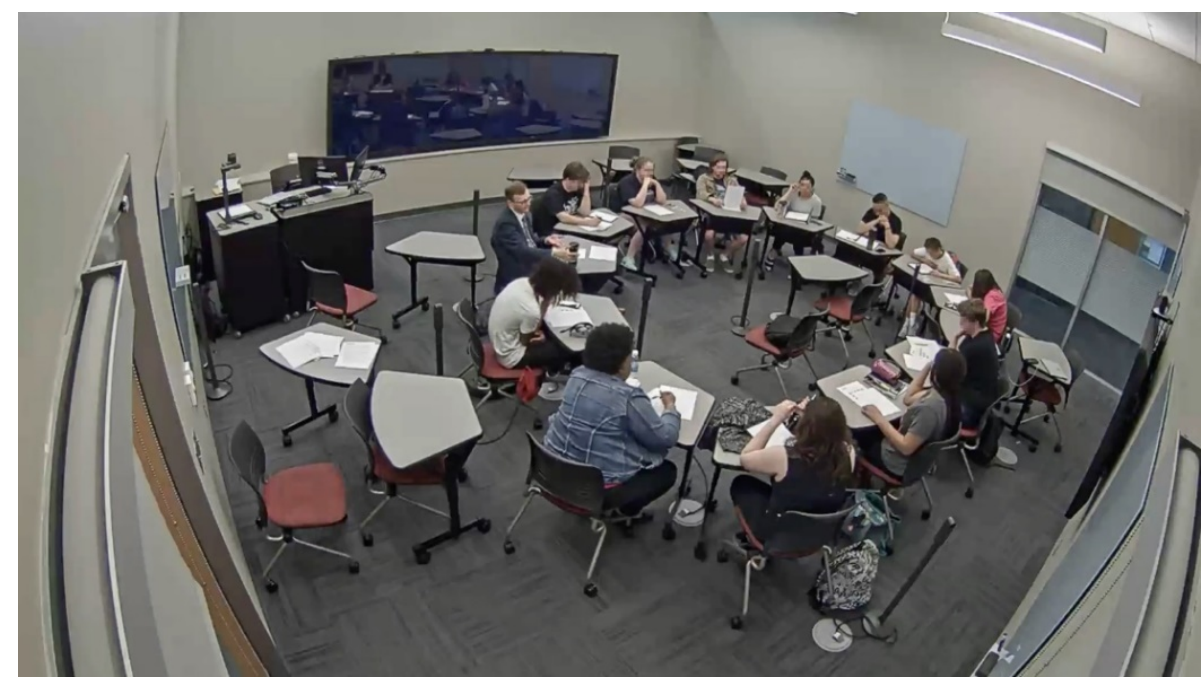

Figure 3. Room arrangement configured to facilitate seminar discussion on student texts.

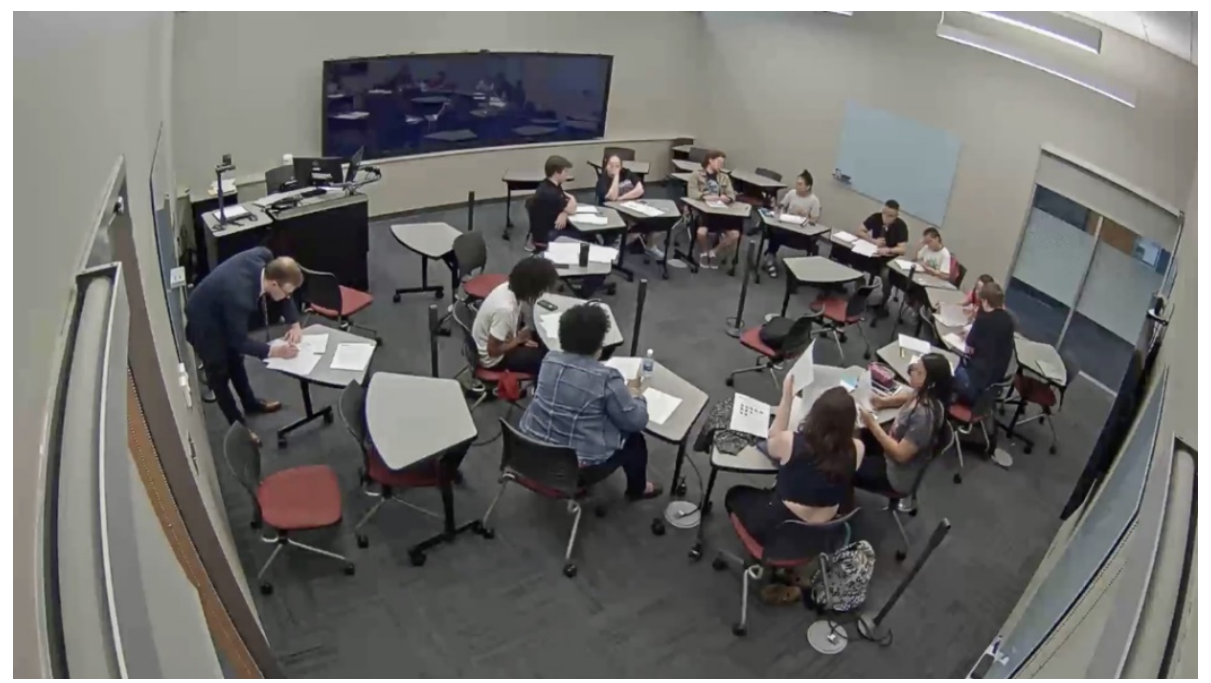

Figure 4. Students turn to work with partners to reflect on seminar discussion. 
The key affordance of this nondigital classroom technology is its modularity. The trapezoidal tables were designed to fit next to one another in rows, circles, or pairs, making for easier transitions between configurations. This transition between classroom configurations could be replicated in a variety of physical learning environments.

\section{Shuttling Between Page and Screen}

Overview and goals. Shuttling between page and screen is an activity that uses paper documents to identify course concepts and digital technologies to productively complicate the concepts. The goal of shuttling between page and screen is to enhance discussions with interactive examples that highlight the differences among media. In first-year composition, an instructor might use this activity to explore how the labor of reading and writing is shaped by digital technologies (e.g., How does revising using Microsoft Word differ from revising using a printout?). In other disciplines, an instructor might use this activity to provide more engaging illustrations of course concepts (e.g., augmenting a textbook with additional examples) or to demonstrate research methods (e.g., using a field-specific database to locate a reference).

Connecting digital and nondigital technology. Developing an activity that shuttles between page and screen starts with the identification of a text that will ground classroom interactions in a shared conceptual space. This grounding text-which might be taken from a student writer, a published source, or other instructional materials - is presented to students before the class meeting as a reading assignment. In class, students consult a paper copy of this text in small or large groups. The key affordance of this nondigital technology is replicability. Barring minor variations, one printed document is effectively the same as another-especially if that document is processed by the instructor before distribution. When students examine the document, they have reasonably comparable experiences because the technology functions in the same way for everyone.

The central digital technology in this application is not a screen itself but a screen in conjunction with a device connected to the Internet. In a "shuttling" activity, the screen/device combination is used to display materials suggested or generated by students. These materials might be transferred directly from students' devices or routed through an instructor-controlled interface. The key affordance of this digital technology is its responsiveness. This affordance allows for examples to be suggested and explored in the moment, which, we contend, might create possibilities for unexpected connections. Although the classroom studied in this article benefitted from a large, touchsensitive display, this technology is not necessary for a successful shuttling activity; the activity could be replicated in any classroom with an Internet-enabled device and a data projector or other screen.

In a particularly fruitful class meeting within this design case, students engaged in a shuttling between page and screen activity to explore the affordances of online texts and Dush's (2015) use of content as a metaphor to understand contemporary composing practices. First, they huddled their desks into small groups to identify key terms from Dush's "When Writing Becomes Content" (2015) using paper copies of the article. To facilitate discussion, the instructor wrote down student-suggested key terms on a whiteboard (see Figure 5). 


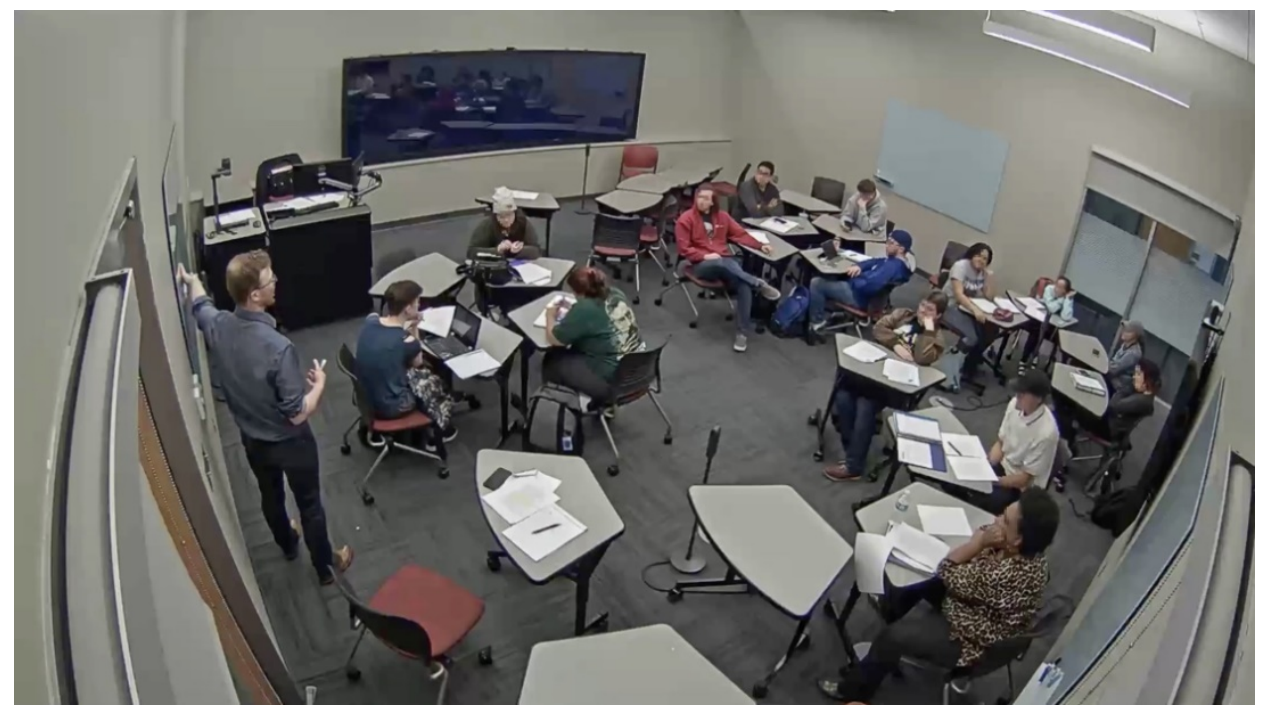

Figure 5. Small-group discussion using paper copies of Dush's (2015) "When Writing Becomes Content" with instructor-facilitated input at whiteboard.

Following the small-group discussion activity, students suggested websites that they might analyze using the key terms they identified. Guided by students' comments, the instructor displayed websites on the screen and then revealed one website's source code (demonstrating its "nature as digital data") and examined another's social media sharing features (exploring the website content's "fluidity in terms of... shape"; Dush, 2015, p. 176). With each key term, attention was drawn from the page (where students took notes) to the screen (where examples were shown and manipulated) and back as students participated in a multimodal engagement with course concepts (see Figure 6).

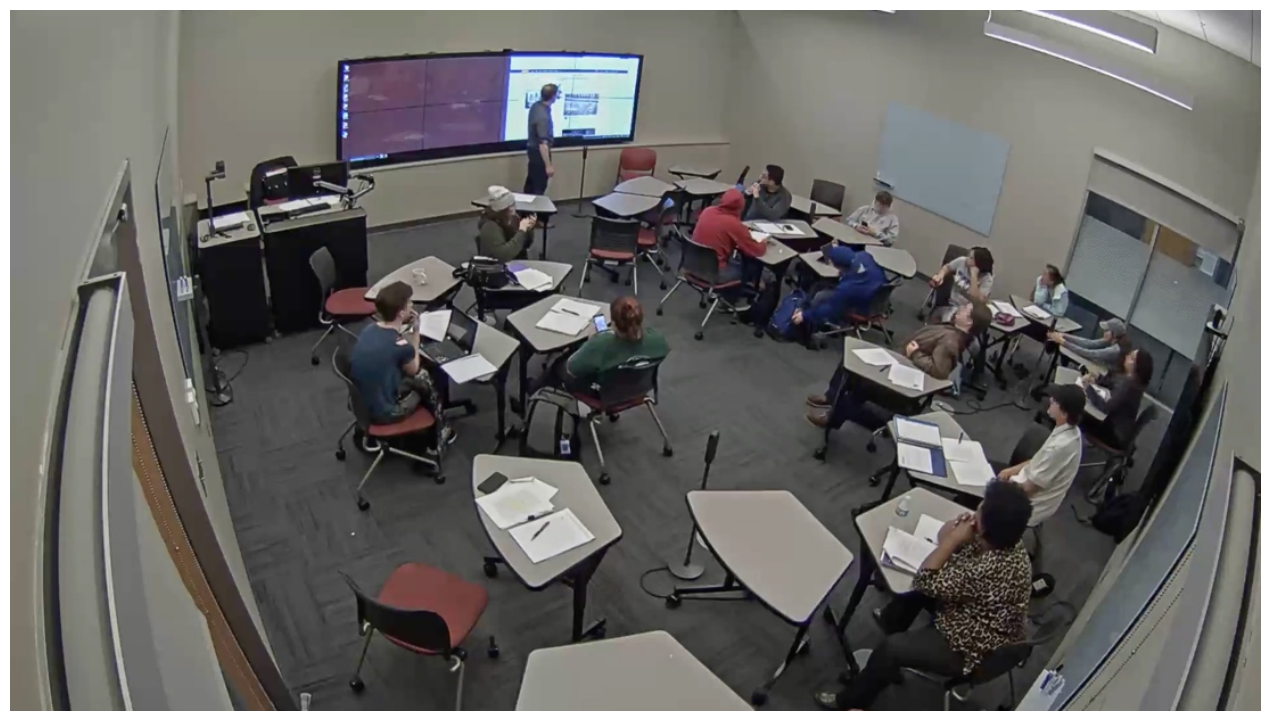

Figure 6. Use of interactive video wall to apply key terms to student-suggested examples.

\section{Networked Note Making}

Overview and goals. The networked note-making activity asks students to discuss a paper document and then to work together to translate their discussion into writing using Web-based word processing software. The goal of this activity is to capture ideas shared in class in a form that can be 
revisited by students both in and out of class. In first-year composition and other disciplines, this technique might be used to document class discussions, to model note-taking practices, and to build connections across meetings.

Connecting digital and nondigital technology. This activity begins by identifying a paper-based grounding text. As with the shuttling between page and screen activity, the grounding text might be taken from a student writer or other source and should be incorporated into a reading assignment either before or during the class meeting. The key affordance of this nondigital technology is, as before, the replicability that allows students to have a comparable experience with the document and a shared point of reference for class discussion.

The central digital technology of this activity is the Web-based word processor that is used to capture and/or represent work completed in the classroom. This software should be continuously available during the class meeting to encourage use. As in the anonymized student writing activity, the key affordance of the Web-based word processor is its computability; unlike in the earlier activity, computability is marshaled for the purposes of recording, storing, and sharing writing rather than formatting it. The nondigital and digital technologies work together in this activity to create multiple entry points for students to engage with course concepts.

In one recorded class meeting, students were asked to use a networked note-making activity to collaboratively define assessment criteria for an upcoming assignment. They were given a paper copy of a rubric created by the university's writing program administration and used across all sections of the course. In groups, the students worked together to identify key terms and type them into a shared Google Docs file using their personal devices. Rather than nominate a single student to work with the Google Doc, two of the three groups elected to have multiple group members contribute to the document simultaneously (see Figure 7). Because the document was shared across all students, the instructor was able to monitor their progress on his workstation and, after small group discussion had finished, project their work on the video wall for full class discussion. At the end of the class meeting, students had a paper copy of the rubric as well as a digital copy of classroom notes from multiple small groups. Ideally, these two technologies could be used by students outside of class to better understand their upcoming assignment.

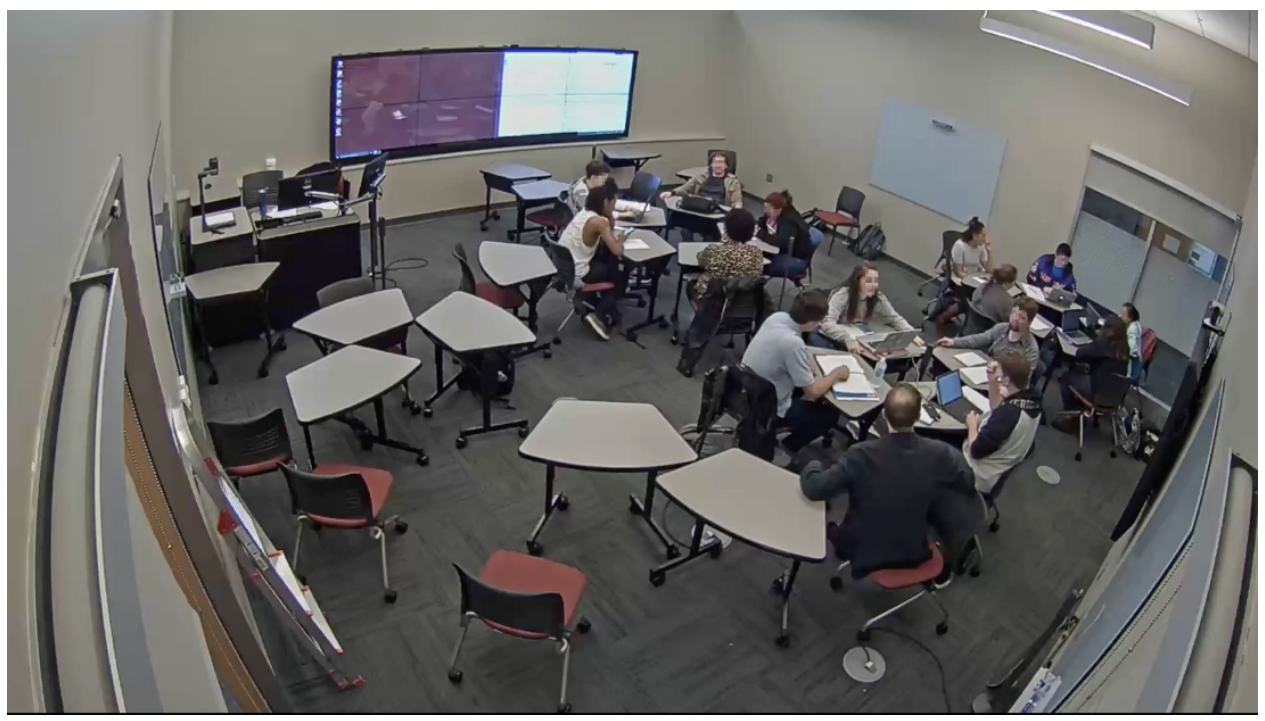

Figure 7. Students contribute to a group networked note-making activity using personal mobile devices. 


\section{Future Directions}

This article describes an approach to writing instruction that seeks to build connections between digital and nondigital technologies with a special focus on paper-based student writing. We argue that understanding paper-based student writing as a technology — that is, as a socially situated, material object that mediates activity — draws attention to the affordances of these documents, affordances that might be used to create active-learning activities such as those described above. In sum, the complex relationship of writing and technology presents opportunities to promote active learning in physical learning environments.

While our research was restricted to a first-year composition course, we posit that each of these activities might be adapted to courses from other disciplines. For example, anonymized student writing about an economic principle might be used to facilitate an in-class discussion grounded in student interest in and (mis)understanding of that principle. One future direction for research and practice might be to take these approaches to student writing to other disciplines to see how they operate in these contexts.

Another future direction might be to adapt the broader approach to understanding paper texts as technologies to different physical learning environments. Although the design case described in this article was set in a technology-rich ALC, the approach to connecting nondigital and digital technologies might be similarly useful in a more "traditional" classroom. For example, the networked note-taking activity could be applied within a classroom with a data projector, a standard monitor, or no shared screen at all. So long as students have access to paper documents and an Internet-connected device, connections between digital and nondigital technology can be made. We hope these future directions underscore our argument that understanding paper-based writing as a technology might be a useful approach to designing active-learning activities.

\section{References}

Baepler, P., Walker, J. D., Brooks, D. C., Saichaie, K., \& Petersen, C. I. (2016). A guide to teaching in the active learning classroom: History, research, and practice. Sterling, VA: Stylus.

Boling, E. (2010). The need for design cases: Disseminating design knowledge. International Journal of Designs for Learning, 1, 1-8. https://doi.org/10.14434/ijdl.v1i1.919

Brooks, D. C. (2011). Space matters: The impact of formal learning environments on student learning. British Journal of Educational Technology, 42, 719-726.

Bruce, B., \& Hogan, M. (1998). The disappearance of technology: Toward an ecological model of literacy. In D. Reinking, M. McKenna, L. Labbo, \& R. Kieffer (Eds.), Handbook of literacy and technology: Transformations in a post-typographic world (pp. 269-282). Mahwah, NJ: Erlbaum.

Coca, D. M., \& Sliško, J. (2017). Software Socrative and smartphones as tools for implementation of basic processes of active physics learning in classroom: An initial feasibility study with prospective teachers. European Journal of Physics Education, 4, 17-24.

Derry, S. J., Pea, R. D., Barron, B., Engle, R. A., Erickson, F., Goldman, R., ... Sherin, B. L. (2010). Conducting video research in the learning sciences: Guidance on selection, analysis, technology, and ethics. The Journal of the Learning Sciences, 19, 3-53.

Dryer, D. B. (2015). Writing is not natural. In L. Adler-Kassner \& E. Wardle (Eds.), Naming what we know: Threshold concepts of writing studies (pp. 17-34). Logan, UT: Utah State University Press. https://doi.org/10.7330/9780874219906.c001

Dush, L. (2015). When writing becomes content. College Composition and Communication, 67, 173-196. Haas, C. (1996). Writing technology: Studies on the materiality of literacy. Mahwah, NJ: Erlbaum. 
Harris, J. (2010). Workshop and seminar. In J. Harris, J. D. Miles, \& C. Paine (Eds.), Teaching with student texts: Essays toward an informed practice (pp. 145-157). Logan, UT: Utah State University Press.

Howard, C. D., Boling, E., Rowland, G., \& Smith, K. M. (2012). Instructional design cases and why we need them. Educational Technology, 52(3), 34-38.

Koehler, M. J., \& Mishra, P. (2009). What is technological pedagogical content knowledge? Contemporary Issues in Technology and Teacher Education, 9, 60-70.

Manovich, L. (2001). The language of new media. Cambridge, MA: MIT Press.

Ong, W. J. (2002). Orality and literacy: The technologizing of the word. London, England: Routledge. (Original work published 1982)

Pea, R. D. (2006). Video-as-data and digital video manipulation techniques for transforming learning sciences research, education, and other cultural practices. In J. Weiss, J. Nolan, \& P. Trifonas (Eds.), International handbook of virtual learning environments (pp. 1321-1393). Dordrecht, The Netherlands: Kluwer Academic.

Prendergast, C., \& Ličko, R. (2009). The ethos of paper: Here and there. JAC, 29, 199-228.

Roman, T. A., \& Uttamchandani, S. (2018). Researching pedagogy within small active learning classrooms: Examining enacted pedagogies of learner and instructor interactions. International Journal of Research \& Method in Education, 41, 447-467.

Russell, D. R. (1997). Rethinking genre in school and society: An activity theory analysis. Written Communication, 14, 504-554. https://doi.org/10.1177/0741088397014004004

Saldaña, J. (2015). The coding manual for qualitative researchers (3rd ed). Thousand Oaks, CA: Sage.

Shipka, J. (2011). Toward a composition made whole. Pittsburgh, PA: University of Pittsburgh Press.

Smith, K. M. (2010). Producing the rigorous design case. International Journal of Designs for Learning, 1, 9-20. https://doi.org/10.14434/ijdl.v1i1.917

Star, S. L. (1990). Power, technology and the phenomenology of conventions: On being allergic to onions. The Sociological Review, 38(1_suppl), 26-56. https://doi.org/10.1111/j.1467954X.1990.tb03347.x

University Information Technology Services. (2019). Immersive showcase classroom. Retrieved from https://uits.iu.edu/learning-spaces/immersive

W131: Reading, writing, and inquiry. (2018). [Course description]. Retrieved from https://liberalarts.iupui.edu/english/pages/writing-program-folder/courses.php\#rtab2

Wardle, E. (2007). Understanding "transfer" from FYC: Preliminary results of a longitudinal study. WPA: Writing Program Administration, 31, 65-85.

Yip, J., Wong, S. H., Yick, K. L., Chan, K., \& Wong, K. H. (2019). Improving quality of teaching and learning in classes by using augmented reality video. Computers \& Education, 128, 88-101. 